\title{
Gapinha, Gapeta, Gapão: uma câmera cotidiana
}

\author{
Rosane Jesus, Michele Oliveira, Hélio Pereira, Jones Souza \\ \& Márcia Bello*
}

Resumo: Com a base teórico-filosófica de Guattari (2001) na compreensão de ecosofia e no veio metodológico da etnografia por Geertz (2008) e Clifford (2011), este artigo narra o processo de produção do documentário etnográfico Gapinha, Gapeta, Gapão, que apresenta os impactos do Grupo Ambientalista de Palmeiras nos agenciamentos intersubjetivos dos moradores de uma comunidade.

Palavras-chave: ecosofia; etnografia; documentário.

Resumen: Partiendo de la base teórico-filosófica de Guattari (2001) en la comprensión de la ecosofía, y siguiendo la senda metodológica de la etnografía de Geertz (2008) y Clifford (2011), este artículo narra el proceso de producción del documental etnográfico Gapinha, Gapeta, Gapão, que presenta el impacto del Grupo Ambiental de Palmeiras en los agenciamientos intersubjetivos de los habitantes de una comunidad.

Palabras clave: ecosofía; etnografía; documental.

Abstract: Supported by the theoretical and philosophical approach by Guattari (2001) in understanding ecosophy and the methodological ethnography by both Geertz (2008)

* Rosane Meire Vieira de Jesus: Universidade do Estado da Bahia, Departamento de Educação/Campus XIV, Grupo de pesquisa Formação, Experiência e Linguagens - FEL/CNPq. 48730-000, Conceição do Coité, Brasil. E-mail: rosanevieiraj@gmail.com

Michele Cerqueira de Oliveira: Graduado em Comunicação Social, Universidade do Estado da Bahia, Departamento de Educação/Campus XIV, Grupo de pesquisa Formação, Experiência e Linguagens - FEL/CNPq. 48730-000, Conceição do Coité, Brasil. E-mail: michelepa569@gmail.com

Hélio Libório Pereira: Graduado em Comunicação Social, Universidade do Estado da Bahia, Departamento de Educação/Campus XIV, Grupo de pesquisa Formação, Experiência e Linguagens (FEL/CNPq). 48730-000, Conceição do Coité, Brasil. E-mail: prhelio2016@gmail.com

Jones Nascimento Souza: Graduado em Comunicação Social, Universidade do Estado da Bahia, Departamento de Educação/Campus XIV, Grupo de pesquisa Formação, Experiência e Linguagens - FEL/ĈNPq. 48730-000, Conceição do Coité, Brasil. E-mail: nascimentojones@ hotmail.com

Márcia Andrade Oliveira Bello: Mestranda em Educação pelo Programa de PósGraduação em Gestão e Tecnologia Aplicadas à Educação - GESTEC, Universidade do Estado da Bahia, Departamento de Educação/Campus XIV, Grupo de pesquisa Formação, Experiência e Linguagens - FEL/CNPq. 48730-000, Conceição do Coité, Brasil.E-mail: marcia.bello2014@gmail.com

Submissão do artigo: 01 de junho de 2016. Notificação de aceitação: 30 de agosto de 2016. 
and Clifford (2011), this article narrates the production process of the ethnographic documentary Gapinha, Gapeta, Gapão which presents the impact of the Environmental Group of Palmeiras in the inter-subjective assemblages of the inhabitants of a community.

Keywords: ecosophy; ethnography; documentary.

Résumé: Avec la base théorique et philosophique de Guattari (2001) pour la compréhension de l'écosophie et à partir de la méthodologie ethnographique de Geertz (2008) et Clifford (2011), cet article relate le processus du documentaire ethnographique Gapinha, Gapeta, Gapão qui présente l'impact du Groupe environnemental de Palmeiras dans les assemblages inter-subjectifs des habitants d'une communauté. Mots-clés : ecosophy ; ethnographie ; documentaire.

\section{Uma introdução}

A preocupação com as questões ambientais figura em debates nos mais variados setores da sociedade. Algumas expressões são emblemáticas nestas discussões: "Precisamos cuidar do planeta Terra para nossa sobrevivência", "Os jovens devem ser educados para uma postura ética com a Natureza", "Os consumidores necessitam ser orientados a incorporar a consciência ambiental como critério na escolha de produtos e serviços, independentemente dos valores" ou "O desenvolvimento econômico e social precisam ser sustentáveis". Mas como podemos promover estas mudanças transformando indivíduos preocupados com seus desejos pessoais em "cidadãos" ambientais? A Educação Ambiental (EA) tem sido a resposta fácil a estas demandas. Expressão de fácil entendimento, que parece dispensar maiores apresentações e reflexões. Então toda e qualquer ação educativa que tenha por objetivo a proteção da natureza é denominada de Educação Ambiental. Em várias outras áreas, e não seria diferente com a EA, conceitos simplificados escondem questões de fundo.

A preocupação de como o meio ambiente tornou-se proeminente na agenda das sociedades contemporâneas indica a possibilidade de que o paradigma moderno não consegue dar conta da degradação crescente e permanente do homem ao ambiente natural, no seio das relações sociais e subjetivas. No processo societário, os indivíduos, com base numa visão utilitarista da natureza, almejam um desenvolvimento econômico com preservação do meio ambiente para as próximas gerações. Esta ética antropocêntrica de dominação da natureza foi identificada por Mauro Grun (2007: 27), já no discurso de Francis Bacon, como permissão exploratória "pois a Natureza deve e necessita ser posta a serviço do homem, feita escrava e moldada pelas artes mecânicas".

A EA surge como forma de (re)estabelecer a conexão homem-ambiente, uma fórmula mágica e redentora dos "pecados", oriundos da racionalidade antropocêntrica. Parte integrante do arcabouço legal nacional desde a Constituição Federal de 1988, a EA vem sendo, nas últimas décadas, preconizada nas políticas públicas como instrumento de resolução da crise provocada pelo paradigma moderno civilizatório.

Entretanto, a Política Nacional de Educação Ambiental (PNEA), Lei 9.795/ 1999, indica uma permanência deste rumo para a EA ao formulá-la como um processo vol- 
tado para "a conservação do meio ambiente, bem de uso comum do povo, essencial à sadia qualidade de vida e sua sustentabilidade" (Brasil, 2011). Estas compreensões apontam para uma essência antropocêntrica no arcabouço conceitual das políticas públicas para a EA.

Com base nessas pistas, este artigo aborda a dimensão ambiental como objeto de estudo teórico-epistemológico, tensionando a forma como o documentário $\mathrm{Ga}$ pinha, Gapeta, Gapão, através da prática etnográfica, traça contornos de uma articulação ético-política e existencial da dimensão ambiental, nas suas complexidades, in-tencionando fugir de discursos românticos e/ou moralistas, que pendulam entre a ideia de recurso para sustentabilidade à deificação da natureza. Essa articulação éticopolítica contempla o meio ambiente, a relação entre os indivíduos e a subjetividade dos humanos, como uma dialogicidade ambiental.

\section{Documentário e etnografia}

O ponto de partida desse trabalho é o Grupo Ambientalista de Palmeiras (GAP), que fica na cidade baiana de Palmeiras, no Parque Nacional da Chapada Diamantina. O GAP é fruto da ideia de um coletivo preocupado com o ambiente natural e social do município de Palmeiras, voltando-se para os seguintes objetivos: arborização da cidade, brigada voluntária de combate aos incêndios na chapada, coleta e reciclagem, inclusão digital dos moradores carentes da região e conscientização da população sobre o descarte correto do lixo.

Atualmente, o grupo é uma referência socioambiental na Chapada Diamantina; luta contra a degradação do meio ambiente e pela preservação e conservação dos recursos naturais da cidade de Palmeiras, desde a década de 1980, com a premissa de que a cidade não se acomode com as políticas governamentais socioambientais, mas, em coletividade e com acesso à informação, possam fomentar projetos e intervenções na comunidade. O GAP tem proporcionado experiências na comunidade, promovendo uma série de alterações existenciais.

É importante evidenciar que a ONG visa reinventar a maneira de ser dos habitantes da região por meio da prática, ao invés do que chamaríamos de EA. Compreendem que uma ação poderia provocar transformação, ruptura, no modo de viver das pessoas de Palmeiras, em defesa de uma cidade mais reflexiva daquilo que se faz, que se come e dos seus destinos finais do lixo.

Nesse sentido o documentário Gapinha, Gapeta, Gapão ${ }^{1}$, produzido por três estudantes de Comunicação Social como Trabalho de Conclusão de Curso, intentou trazer cenas que demonstrem como a ONG, por meio do seu trabalho, proporcionou uma ruptura na maneira de agir dos habitantes de Palmeiras, com vistas ao cuidado com o meio ambiente.

Para tanto optaram por utilizar a etnografia com a pretensão de captar como esses cuidados são um aspecto cultural. A equipe de documentaristas ficou quinze dias na cidade para se "encharcar" de cotidiano. As gravações espontâneas aproximam o

1. Gapinha, Gapeta, Gapão remete a um programa de rádio criado com vistas à disseminação do trabalho do GAP, anos atrás. 
documentário etnográfico do modo de representação observativo, na classificação de Bill Nichols (2005: 148): “O modo observativo propõe uma série de considerações éticas que incluem o ato de observar os outros se ocupando dos seus afazeres". Isto é, observar o espontâneo é reconhecer e apresentar a história do personagem como mais importante que a do realizador.

Sempre que as forças culturais de um sujeito agem sobre a estrutura de um filme - através da padronização de um acontecimento, de uma narrativa pessoal, da apropriação de uma função local, ou de alguma outra forma - o filme pode ser lido como um trabalho composto, um cruzamento de perspectivas culturais. Algumas vezes o processo não vai adiante. Estamos acostumados a ver nos filmes por detrás dos pressupostos (pontos de vista) do realizador aqueles das pessoas filmadas, e temos consciência da sua ilegalidade mútua. (Macdougall apud Barbosa et al., 2009:141).

Para além das imagens das ações espontâneas dos habitantes de Palmeiras, foram captados depoimentos de pessoas ligadas diretamente à $\mathrm{ONG}$, na forma de entrevistas semiestruturadas para que os depoentes, como atores sociais, ficassem livres para discorrer diante da câmera: "o entrevistado tem a possibilidade de discorrer sobre o tema em questão sem se prender a indagação formulada” (Minayo, 2012: 64).

As 'pessoas' são tratadas como atores sociais: continuam a levar a vida mais ou menos como fariam sem a presença da câmera. Continuam a ser atores culturais e não artistas teatrais. Seu valor para o cineasta consiste não no que promete uma relação contratual, mas no que a própria vida dessas pessoas incorpora. (Nichols, 2005: 31)

Logo, para perceber as ações espontâneas dos habitantes da região, no que diz respeito à forma como lidam com as questões ambientais, colocadas em pauta pelo GAP, foi necessário voltar-se para as marcas culturais e a interpretação das práticas, da forma como o grupo ambientalista de Palmeiras trabalha e conscientiza a população daquela região, o seu agir no meio ambiente. Assim a opção pela etnografia, como registro cultural a ser interpretado por quem vive e por quem observa, é estruturante (Clifford, 2011).

A equipe de documentaristas se colocou atenta aos acontecimentos, se entrosando à comunidade e interpretando as práticas percebidas na observação que:

(...) serve como uma fórmula para o contínuo vaivém entre o "interior" $\mathrm{e}$ o "exterior" dos acontecimentos: de um lado, captando o sentido de ocorrências e gestos específicos, pela empatia; de outro, dá um passo atrás, para situar esses significados em contextos mais amplos. Acontecimentos singulares, assim, adquirem uma significação mais profunda, ou mais geral, regras estruturais, e assim por diante. (Clifford, 2011: 32)

Resumindo, os textos antropológicos são eles mesmos interpretações e, na verdade, de segunda e terceira mão. (por definição, somente um "nativo" faz a interpretação em primeira mão: é a sua cultura). Trata-se, portanto, de ficções; ficções no sentido de que são "algo construído", "algo modelado" o sentido original de fictício - não que sejam falsas, não-factuais ou apenas experimentos de pensamento. (Geertz, 2008:11).

Fazer etnográfica, em sua essência, já consiste em experienciar lugares, pessoas e crenças; é a experiência nascida do encontro com o outro. Nas concepções de Jean 
Rouch, o documentário etnográfico é similar à pesquisa escrita mais comumente utilizada no estudo etnográfico, porém com um acréscimo: a imagem, que vem somar-se ao caderno de notas.

Ora o filme etnográfico inspira-se, curiosamente, nessa mesma relação perigosa com o mundo vivido. Filmar o ritual, ato alternativo e complementar à etnografia verbal, é, nesse sentido, menos retratá-lo (representá-lo) do que potencializá-lo, amplificá-lo, deixar se afetar por ele. (Barbosa et al., 2009: 244)

É importante ressaltar que, em todas as cenas, tanto a captação de áudio quanto a de som foram pensados buscando o natural que o ambiente oferecia (som ambiente); bem como a iluminação foi natural. O que aproxima o documentário etnográfico da concepção de cinema verdade de Jean Rouch: "o cinema em tomada direta sobre a realidade" (Rouch apud Da-Rin, 1995: 115). O olhar observador da equipe ficava na expectativa da captação da mise-en-scène própria das pessoas gravadas.

Nessa linha, pode-se dizer que, por meio da captura do instante, do vivido dos habitantes da Região de Palmeiras, pretenderam produzir um documentário que proporcionasse ver o GAP como um espaço sociopolítico que busca de forma colaborativa resoluções para os problemas ecológicos, objetivando impactar nas práticas sociais uma postura ético-estética e existencial de compreensão do ser como participante do meio.

\section{Documentário e ecosofia}

O GAP tem proporcionado experiências na comunidade, promovendo uma série de alterações existenciais. Nesse raciocínio, cabe dialogar com o termo filosófico ecosofia de Guattari (2001), quando afirma que a prática, o fazer é mais impactante quando se pretende conscientizar as pessoas; elas devem se sentir tocados no seu agir, uma vez que essa prática marca a existência de cada um. Guattari mostra uma peculiar sensibilidade acerca do campo conceitual do ambiente. De forma especial, um conceito teorizado por ele é fundante neste trabalho: a ecosofia. Avança onde educadores, filósofos e demais ambientalistas não perceberam - incluir a subjetividade humana no meio ambiente. Mas o que torna tão caro o conceito de ecosofia para compreender este documentário?

Guattari (2001: 8) a define como "uma articulação ético-política entre os três registros ecológicos (o do meio ambiente, o das relações sociais e o da subjetividade humana)" para a enfrentamento da crise ecológica atual. Estas três rubricas de recomposição são percebidas numa lógica diferente, que se afasta daquela dos conjuntos discursivos que delimitam seus objetos para a lógica das intensidades ou eco-lógica que realiza um movimento (des)construção, de desterritorialização.

Neste aspecto, Guattari, ao alertar os operadores "psi”, atenta para a insustentabilidade da postura de neutralidade de uma pseudocientificidade. Ele adverte do potencial agenciamento subjetivo individual e coletivo destes operadores para convergir na perspectiva com o mundo das artes e se afastar das influências das "ciências duras" (Guattari, 2001: 23). 
Este referencial teórico serve como baliza para se opor a um cientificismo pivotante percebido no campo conceitual da EA, que se realiza em narrativas unívocas para uma dimensão ambiental como uma cadeia semiótica que se multiplica em diversos atos, signos e radículas na percepção sobre meio ambiente. No documentário Gapinha, Gapeta, Gapão, não são expostos ambientalistas renomados que, na maioria, estão preliminarmente ligados ao viés da economia e do lucro, mas mostram que quem resolve os problemas ambientais da região são os próprios habitantes, voluntários do GAP. Numa crítica à perspectiva tecnocrática, Guattari (2001: 24) afirma que "Não podemos nos deixar guiar cegamente pelos tecnocratas dos aparelhos de Estado para controlar as evoluções e os riscos nesses domínios, regidos no essencial pelos princípios da economia e do lucro".

A ecosofia é um pressuposto ético-estético para compreender as práticas que reinventam as posturas e as relações do cidadão na sociedade, dele consigo mesmo e dele com o meio ambiente, mesmo diante dos avanços tecnológicos, caracterizado por Guattari como mecanosfera. Por meio da etnografia, esse documentário mostra as posturas dos habitantes da região frente as suas ações ecológicas, práticas como registros culturais, já que somos todos praticantes culturais. "Mais do que nunca a natureza não pode ser separada da cultura e precisamos aprender a pensar transversalmente as interações entre ecossistemas, mecanosfera e Universos de referência sociais e individuais". (Guattari, 2001: 25)

O agir humano é formado por processos subjetivos que caracterizam os dois tipos de ecosofia: a ecosofia social e a ecosofia mental. A social está relacionada às posturas dos indivíduos, ou melhor, à reconfiguração de práticas individuais e coletivas dos mesmos diante da mecanosfera que é caracterizada pelo avanço técnico-industrial da contemporaneidade. Esses avanços, para o autor, trazem grandes impactos para as relações sociais, causando a perda da outridade e das relações afetivas entre vizinhos e familiares.

A Ecosofia mental, por sua vez, está atrelada aos processos subjetivos do subconsciente individual ou coletivo que, no entanto, se formam com vistas no mundo exterior; são interdependentes. Essa relação do mundo interno em consonante com ao mundo externo é provocado por um sentimento mútuo, espontâneo e intuitivo do homem em resposta ao conceito, teoria e afetividade na implicação do que move as mudanças perceptíveis pelo impacto do hábito. Ou seja, as transformações acontecem não por uma imposição, mas um engajamento de transformação, em que o conceito, o afeto e o percepto estão interligados para uma práxis, como uma prática engajada.

Se não se trata mais - como nos períodos anteriores de luta de classe ou de defesa da "pátria do socialismo" - de fazer funcionar de maneira unívoca, é concebível em compensação que a nova referência ecosófica indique linhas de recomposição das práticas humanas nos mais variados domínios. Em todas as escalas individuais e coletivas, naquilo que concerne tanto a vida cotidiana quanto à reinvenção da democracia - no registro do urbanismo, da criação artística, do esporte etc - trata-se, a cada vez, de se debruçar sobre o que poderia, ser os dispositivos de produção de subjetividade, indo no sentido de uma re-singularização individual e/ou coletiva, ao invés de ir no sentido de uma usinagem pela mídia sinônimo de desolação e desespero. (Guattari, 2001: 14) 
Relacionar a natureza à vida humana é afirmar um comprometimento direto do homem com o meio ambiente, direcionando as vivências às subjetividades. Essa relação ainda não é possível de forma efetiva, pois o homem não foi preparado para perceber os problemas ecológicos como questões culturais e sociais de uma região, que se revelam no cotidiano.

\section{Documentário Gapinha, Gapeta, Gapão}

Depois de horas de vídeo, captadas nas gravações feitas em quinze dias, o documentário tem a duração de doze minutos. De forma não linear, o documentário é composto basicamente por entrevistas, ações espontâneas dos moradores de Palmeiras e imagens de arquivo do GAP.

Como prólogo do documentário, há a I Parte - Cidade de Palmeiras. O foco central é a ambientação da cidade de Palmeiras, situada na Chapada Diamantina, na Bahia. Apresentam a diversidade cultural e turística da cidade e sua cordialidade como cidade receptora de toda região rica em diversidade natural. Além das imagens de ambientação, a declamação do hino da cidade de Palmeiras na voz de Dona Amanda, poeta da cidade, em sua casa, aproxima o espectador da cidade. Em outra cena, a simpatia de Dona Amanda convida os espectadores para a praça central de Palmeiras, dançando na festa de aniversário de sua cidade. Esse momento logo aponta para a importância da reeducação sobre o lixo que produzimos. Vê-se Dona Amanda segurando uma latinha de cerveja e um copo descartável em suas mãos até o momento certo de descartá-los. Seu cuidado e contribuição aos 72 anos de idade são exemplo de sua consciência ambiental.

Depois vem a II Parte - Os Loucos. Essa parte marca o quanto enfrentar comportamentos historicamente construídos é coisa para "loucos". Os integrantes do GAP e seus voluntários são loucos por se desafiarem a ter outro estilo de vida contraditório ao cotidiano de uma sociedade capitalista que destrói a natureza e a relação íntima do homem com o natural. A segunda parte volta-se para o cotidiano nada convencional. Inicia com a homenagem de uma revista nacional a Joás Brandão ${ }^{2}$. Posteriormente, imagens do próprio Joás entrando em um banheiro seco, ecologicamente correto, e explicando o que isso significa. Concomitante, ouve-se a explanação de Jader Cruz dos Santos ${ }^{3}$ sobre seu cotidiano e de que forma ele foi inserido nesse processo de reciclagem do lixo e rearborização; e veem-se imagens de várias ações de mulheres voluntárias do GAP, recolhendo os lixos recicláveis.

Ainda na segunda parte, outra "louca" fala: Drica Rocha ${ }^{4}$, também voluntária da ONG. Ela expõe como se deu seu processo de conscientização ecológica, relatando toda problemática envolvida nos diversos processos de descarte de resíduos sólidos de natureza degradante ao meio ambiente, deixados por pessoas que fazem trilhas nas diversas localidades de zona de turismo de Palmeiras. Seu discurso é alinhado a um passeio por trilhas da região, onde a personagem faz esse papel de recolher resíduos sólidos deixados nas trilhas pelos turistas.

2. Presidente fundador do GAP, mora em Palmeiras há 52 anos, idade que possui.

3. Associado do GAP, mora em Palmeiras desde seu nascimento, 39 anos.

4. Artista multifuncional e yoga massagem, mora em Palmeiras há 3 anos. 
Na III parte - Grupo ambientalista de Palmeiras, Joás Brandão narra sobre o surgimento da ONG, narrando como se deu os primeiros passos, por meio de suas ações, do que seria o GAP; fala das pessoas que ali se engajavam pela causa; suas lutas e desafios. Aqui são mostrados imagens de arquivo da própria ONG.

A IV parte - Problemática do lixo: não existe o fora trata, especificamente, do lixo e de todo processo que é necessário para que haja uma transformação a partir do que se compra ao que se alimenta, visto que é necessário pensar na redistribuição dos resíduos, se incluindo como parte do processo. Sua narrativa é intercalada por meios de ações internalizadas de palmeirenses: imagens de ambientação, feira livre, praça e trechos de entrevista com Drica Rocha, tratando do que é esse novo momento de ruptura na sua vida em que se coloca como parte do lixo. Nessa parte, humanizam o lixo.

E a última parte, V parte - Somos o mundo, traz a possibilidade de a sociedade enveredar por caminhos mais éticos e estéticos ao tratar da relação do homem com o ambiente natural.

\section{Considerações finais}

Por meio de uma atitude etnográfica, percebe-se o quanto a complexidade aparece no olhar documental. Com o deslocamento da equipe de documentaristas até o campo, vivenciaram como uma ONG pode construir efetivamente com os habitantes do lugar um agir mais ecológico, logo uma mudança existencial.

Longe de especialistas sobre educação ambiental, o documentário Gapinha, Gapeta, Gapão busca aventuras individuais transformadoras e, portanto, coletivas, porque são histórias de vida que se colocam em relação com a natureza, sem objetificá-la. Produzir esse documentário etnográfico foi só o início da compreensão do fazer etnográfico. Ir a campo para desbravar o cotidiano é de fato um processo gestacional: transformar horas de gravações e relatos das pessoas de Palmeiras de quinze dias em doze minutos; saber escolher as cenas sínteses; editar sem prejudicar a relação intrínseca com o real concreto do documentário etnográfico.

A cena do encontro na etnografia é a tradução das mine-em-scène dos atores sociais do documentário, pois a equipe de documentaristas não buscou refletir acerca dos cuidados que se deve demonstrar com o meio ambiente, mas buscou fascinar os espectadores com exemplos de pessoas que vivem tais ações.

\section{Referências bibliográficas}

Barbosa, A.; Cunha, E. T. \& Hikiji, R. S. (Orgs.) (2009). Imagem-conhecimento: Antropologia, cinema e outros diálogos. Campinas-SP: Papirus.

Brasil. (2011). Decreto 4.281, de 25.06.2002. Regulamenta a Lei no 9.795, de 27 de abril de 1999, que institui a Política Nacional de Educação Ambiental, e dá outras providências.

Clifford, J. (2011). A Experiência Etnográfica: sobre a autoridade etnográfica. $4^{\mathrm{a}} \mathrm{ed}$. Rio de Janeiro: Editora UFRJ. 
Da-Rin, S. (1995). Espelho partido: tradição e transformação no cinema Documentário. Rio de Janeiro: dissertação de mestrado, Universidade Federal do Rio de Janeiro.

Geertz, C. (2008). A Interpretação das Culturas. Rio de Janeiro: LTC.

Grün, M. (2007). Em busca da dimensão ética da educação ambiental. Campinas, SP: Papirus.

Guattari, F. (2001). As Três Ecologias. 11 ${ }^{\mathrm{a}}$ ed. Campinas: Papirus.

Minayo, M. C. (Org.). (2012). Pesquisa Social teoria, método e criatividade. $31^{\mathrm{a}} \mathrm{ed}$. Petrópolis: Vozes.

Nichols, B. (2005). Introdução ao documentário. $5^{\circ}$ ed. Campinas-SP: Papirus. 